\title{
Breast Cancer Apoptosis and the Therapeutic Role of Luteolin
}

Zacharias Fasoulakis ${ }^{1}$, Antonios Koutras ${ }^{1}$, Athanasios Syllaios ${ }^{2 *}$, Dimitrios Schizas ${ }^{2}$, Nikolaos Garmpis², Michail Diakosavvas ${ }^{1}$, Kyveli Angelou' ${ }^{1}$, Georgios Tsatsaris ${ }^{3}$, Athanasios Pagkalos', Thomas Ntounis ${ }^{1}$, Emmanuel N Kontomanolis ${ }^{3}$

${ }^{1} 1^{\text {st }}$ Department of Obstetrics and Gynecology, National and Kapodistrian University of Athens, Alexandra Maternity Hospital, Athens, Greece

${ }^{2}$ First Department of Surgery, National and Kapodistrian University of Athens, Laikon General Hospital, Athens, Greece

${ }^{3}$ Department of Obstetrics and Gynecology, Democritus University of Thrace, Alexandroupolis, Greece

${ }^{4}$ Department of Obstetrics and Gynecology, General Hospital of Xanthi, Xanthi, Greece

*Corresponding author:

Athanasios Syllaios, MD

First Department of Surgery

Laikon General Hospital

National and Kapodistrian University

of Athens, Ag. Thoma 17, Athens

11527, Greece

E-mail: nh_reas@hotmail.com

\section{Rezumat}

\section{Rolul terapeutic al luteolinei în cancerul de sân}

Cancerul de sân reprezintă unul dintre cele mai frecvente trei tipuri de cancer ginecologic, fiecare subtip având profil de risc şi strategii de tratament distincte. Terapia optimă pentru fiecare caz depinde nu numai de subtipul tumorii şi stadiul cancerului, ci şi de preferințele pacientului. Astfel, alegerea terapeutică finală pare complicat de atins. În plus, recidivele frecvente şi efectele estetice au condus la căutarea unor metode mai eficiente şi mai puțin invazive. Intervențiile chirurgicale au devenit mai puțin complexe şi se stabilesc noi medicamente hormonale şi chimioterapeutice, care promit rezultate excelente, fie combinate cu tratament chirurgical, fie utilizate exclusiv. Luteolina este un reprezentant al flavonoidului natural care a dovedit că modulează diferite căi de semnalizare implicate în dezvoltarea cancerului. Date recente demonstrează că luteolina induce moartea celulelor apoptotice prin activitate antioxidantă, acționând ca agent anticancer împotriva diferitelor tipuri de tumori maligne la om, inclusiv cancerul de sân. Scopul acestei revizuiri este de a rezuma cele mai recente date luând în considerare rolul terapeutic al luteolinei în cancerul de sân.

Cuvinte cheie: cancer mamar, luteolină, flavonoid, apoptoză, carcinogeneză, terapie 


\begin{abstract}
Breast cancer represents one of the three most common gynecological cancers, with each subtype having distinct risk profile and treatment strategies. Optimal therapy for each case depends not only on tumor subtype and cancer stage, but also on patient preferences. Thus, the final therapeutic choice seems complicated to be reached. In addition, frequent relapses and the aesthetic effects have led to the search for more effective and less invasive methods. Surgical interventions have become less complex and new hormonal and chemotherapeutic drugs are established, that promise great results, either combined to surgical treatment or used exclusively. Luteolin is a representative of natural flavonoid that has proven to modulate various signaling pathways involved in cancer development. Recent data demonstrate that luteolin induces apoptotic cell death via antioxidant activity, acting as an anticancer agent against various types of human malignancies including breast cancer. The aim of this review is to summarize latest data considering the therapeutic role of luteolin in breast cancer.
\end{abstract}

Key words: breast cancer, luteolin, flavonoid, apoptosis, carcinogenesis, therapy

\section{Introduction}

Expansion or regression of the tumor is based on the balance between apoptosis and cell proliferation. There are two broadly classified mechanisms for cell death, which are necrosis and programmed cell death. Programmed cell death is the genetically programmed procedure of cell suicide in reaction to specific signals, both extracellular and intracellular. Necrosis is differentiated by apoptosis, in regulating not only the appropriate number of cells, but also ensuring that cells of a specific tissue have a distinct morphological profile (1-3).

Recent studies, confirmed that nonapoptotic forms of programmed cell death also occurs. Thus, it is inappropriate to consider apoptosis and programmed cell death the same. The term apoptosis was proposed by Kerr and his associates to explain a morphologically distinctive organized pattern of cell death, while non-apoptotic cell death resembles an unordered cellular explosion, which is traditionally considered as an uncontrolled and random process including apoptosis-like programmed cell death, necroptosis, and autophagy $(2,3)$.

Under a particular situation such as cancer, autoimmune diseases and neurodegenerative disorders, when apoptosis is genetically or chemically inhibited or repressed, programmed necrosis has been observed. Necrosis and apoptosis are not essentially independent pathways. Bcl-2 family of proteins seems to restrain both apoptotic and necrotic mechanisms $(1,2)$.

Despite the variety of treatments available for all types of cancer, effectiveness and safety problems remain, thus affecting both the treatment outcome and the patient compliance (1-3). Phytochemicals and more specificaly polyphenols became a major research object as they showed greater potential regarding breast cancer treatment, due to the outcomes of their use (apoptosis, autophagy, anti-inflammatory and maintaining redox balance) and produce smaller amount of sideeffects (4). In recent years, research is being conducted especially on luteolin, a flavonoid abundantly present in nature, which has anticancer activities that are demonstrated in many cancer types (4).

Luteolin exhibiting anti-inflammatory actions and inducing apoptosis, inhibit the rapid reproduction of cancer cells and seems to confine the possibility of metastasis and angiogenesis (5-7). Moreover, there is evidence that cancer cells under the influence of luteolin are more prone to cytotoxicity, thus suppressing their cell-survival (8). Additionally, antioxidant properties act prophylactically in the 
development of breast cancer $(9,10)$. Some other actions of luteolin include progress hidrance and resonance of regulatory protein expression regarding the cell cycle of breast cancer cells, depending on dosage for a time period of $48 \mathrm{~h}$ and $72 \mathrm{~h}$ (11).

\section{Apoptosis}

The balance between apoptosis and cell proliferation controls normal breast growth. There is strong proof of tumor growth where reduced apoptosis due to uncontrolled proliferation is present. In response to radiotherapy, chemotherapy, and hormonal treatments, the identification of the overall expansion or regression of the tumor is based on the balance between apoptosis and cell proliferation. By inducing apoptosis, all of these perform in part. By investigating apoptosis and its regulation and control along with utilizing these to medical benefit, it is feasible to define the biology of individual tumors at the biochemical and molecular levels. The identification of the way, in which tumor cells evolve apoptosis, to oppose cell death as well as the gained knowledge about the complication of apoptosis mechanism has influenced research into the new approaches designed to persuade apoptosis in cancer cells (12).

In the tissue homeostasis, integrity, and growth of multi-cellular organisms, cell death is acrucial process. In adult organisms, to maintain homeostasis physiological processes, it is crucial for cell proliferation and elimination (13). During the process of tissue turnover, pathogenesis, embryogenesis, and metamorphosis, the unwanted cells are removed. There are two broadly classified mechanisms for cell death, which are necrosis and programmed cell death. Programmed cell death is the genetically programmed procedure of cell suicide in reaction to specific signals (14). A range of intracellular and extracellular signals bounded by the environment of the intracellular signals and cell control the programmed cell death. Programmed cell death involves appropriate regulation in the number of cells in multicellular organisms by removing unwanted cells. It also ensures tissue homeostasis and has distinctive morphological attributes, thus differentiates itself from cell necrosis (15). Programmed cell death in particular cell type starts with the varied exogenous cell-damaging agents and the endogenous tissue-specific agents under decisive physiological circumstances. Infectious agents and physical agents, which react to the majority types of cells cause exogenous activations of the programmed cell death (16). In this regard, infectious agents comprise bacterial toxins and viruses, while physical agents include chemotherapeutic drugs, physical trauma, and radiation. Apoptosis can also be because of internal imbalances such as loss of matrix attachment, healing with glucocorticoids, ablation of a trophic hormone, and growth factors' removal (17). Recent studies have confirmed that non-apoptotic forms of programmed cell death also occurs that has the absence of the mechanism of apoptosis, even though several research groups have frequently associated programmed cell death with apoptosis. Thus, it is inappropriate to consider apoptosis and programmed cell death to be the same. The term apoptosis was proposed by Kerr and his associates to explain a morphologically distinctive pattern of cell death (15).

Apoptosis occurs during morphogenesis and normal cell development along with cell damage or external stress, which is widelyconsidered as animportantsystem of regulated death (16). Diverse groups of the regulatory molecules and executioner firmly regulates apoptosis. Apoptotic cell death usually has the mechanism of action attributes of cell shrinkage, loss of adhesion to extracellular matrices, dynamic membrane blebbing, and fragmentation of DNA occurred in the nucleus, as well as condensation of chromatin material. Moreover, caspases, i.e. the activation of cysteine aspartyl proteases and externalization of phosphatidylserine among other biochemical changes result in cell death (18).

In response to alluring and severe trauma, apoptosis normally differentiates from necro- 
sis that was considered to signify a contradictory way of an unordered cellular explosion (15). The collection of more information on non-apoptotic cell death influences a gradual increase in encouragement in such forms of programmed cell-death. Apoptosis-like programmed cell death, necroptosis, and autophagy are the three types of non-apoptotic cell death. Autophagy (or autophagic cell death) is a self-degradative process and is termed as type II cell death. Inside the dying cell in autophagic vacuoles, autophagic cell death has a crucial role in the degradation of cellular components. Autophagy is extremely prevalent in the invertebrate tissue and is also recognized as vacuolar cell death (19). Necroptosis is originated by the same death signals that persuade apoptosis and is a programmed type of necrotic death. Necroptosis is extremely prevalent in vivo, as death caused by infection, physical traumas, and variedtypes of neurodegeneration (20). Necroptosis (a programmed and regulated type of cell death) and apoptosis have numerous crucial processes. TNFR and FAS among other death receptors (DRs) are recognized to stimulate apoptosis as well as necroptosis in varied cell types. However, when apoptosis has been genetically or chemically repressed or blocked, programmed necrosis has been observed only under a particularsituation. Besides, another type is apoptosis-like programmed cell death that happens in a caspase-independent way, thereby explaining the form of cell death with apoptotic features (21).

In several diseases such as cancer, autoimmune diseases, and neurodegenerative, there is a possibility of causing necrosis. Certain stimuli form of physical damage or toxic trauma typically initiates necrosis, which is traditionally considered as an uncontrolled and random process. The morphological attributes of necrosis morphologically involve bulging of cytoplasm and organelles (endoplasmic reticulum and mitochondria), which causes the disturbance of plasma membrane resulting in the discharge of cellular components and cell lysis. The proliferation of tumors can also happen with cell death by necrosis, associated with chronic inflammation. On the other hand, there is a different insight that the programming of necrosis could also be natural. Only under a particular situation, wherein apoptosis is genetically or chemically inhibited or repressed, the programmed necrosis has been observed. The restrain of both necrotic and apoptotic has been shown by different antiapoptotic proteins of the Bcl-2 family (22). Apoptotic response to a necrotic one can be switched by Intracellular ATP depletion. Thus, necrosis and apoptosis may share some common inhibitors, messengers, as well as activators, and are not essentially independent pathways (15).

\section{Breast Cancer Treatment Challenges}

Despite the variety of treatments available for all types of cancer, effectiveness and safety problems for a lot of them remain, thus affecting both the treatment outcome and the patient compliance (1-3). In addition, it is necessary to examine new approaches, which should be affordable but also effective in reducing the number of both cases and deaths that breast cancer causes in a worldwide scale (23-26). Phytochemicals are a natural agent with preventive and therapeutic action due to their diverse chemical entities. Therefore, they can be used to treat cancer, among other diseases, because of their success in clinical use as they have specialized multimolecular targets and produce smaller amount of sideeffects (27-34).

Although there are several phytochemicals, such as biochanin-A, diindolylmethane, emodin, curcumin, lycopene, rosmarinic acid, epigallocatechin gallate, resveratrol, genistein, sulforaphane, shikonin, rutin, silibinin, poly-phenols became a major research object as they showed greater potential regarding breast cancer treatment due to the outcomes of their use (apoptosis, autophagy, anti-inflammatory and maintaining redox balance) (8,35-41). Apoptosis is considered a major mechanism against cancer, thus 
gained scientific attention as it functions as a mediator to cell death. Autophagy is a process of catabolism in which cytoplasmic components, such as damaged organelles and aged or damaged proteins, are isolated by a double-membrane autophagosome, which distributes them to the lysosome in order to be decomposed. In recent years, research is being conducted especially on luteolin, a flavonoid abundantly present in nature, which has anti-cancer activities that are demonstrated in many cancer types (4).

\section{Luteolin}

Luteolin, a nickname of the scientific term $3^{\prime}, 4^{\prime}, 5$, 7-tetrahydroxyflavone, is a flavonoid that contains several amounts of celery, green pepper and dandelion leaves and is considered thermostable $(8,42)$. It con- $^{-}$ tributes to the beginning of a process that includes apoptosis, cell cycle capture, stifling cell survival signalling, anti-angiogenesis, anti-metastasis, antioxidant, anti-inflammatory, mitigating and hindering cytochrome P450 and focusing on epidermal, platelet derived, insulin-like and fibroblast development factors for its anticancer activity (43). Luteolin's chemical structure consists of one oxygen-containing and two benzene rings as a typical flavonoid (Fig. 1)(8).

\section{Luteolin vs Cancer}

The actions of luteolin could be interrelated with pharmacological activities. For instance, its anti-inflammatory action may be related to its function against cancer. Luteolin's effect during cancer treatment is associated to the incitement of apoptosis, a process that entails redox regulation, DNA damage, and protein kinases in an attempt to avoid rapid reproduction of cancer cells and to confine the possibility of metastasis and angiogenesis (5-7). Moreover, luteolin utilizes a distinct type of cancer cells so they become more sensitive to cytotoxicity as a way of treatment by stimulating the pathways of apoptosis and suppressing those of cell survival (8).

Additionally, according to recent studies luteolin has shown promising signs regarding cancer prevention (44). Lutein is a substance with antioxidant properties that act protectively against reactive oxygen species and decrease the level of oxidative damage of DNA. The aforementioned reactions result in better protection against the emergence of breast cancer $(9,10)$.

Figure 2 illustrates the most recognized mechanism against breast cancer that involves luteolin and consists of two modulations, the apoptosis and the angiogenesis one (8).

By increasing the level of Cytochrome c,

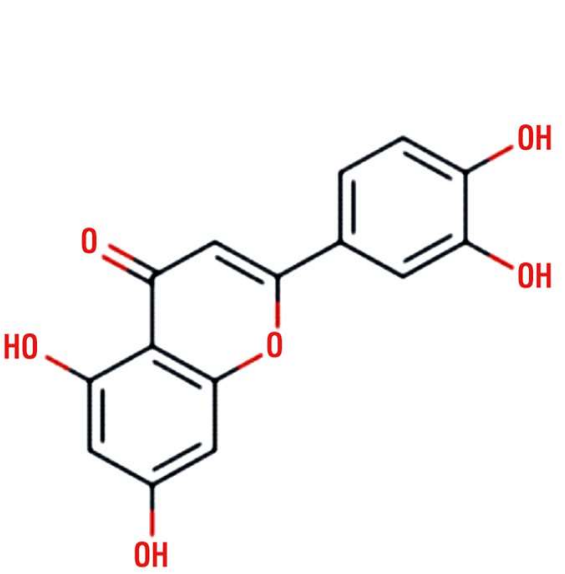

Figure 1. Luteolin's chemical structure (45)

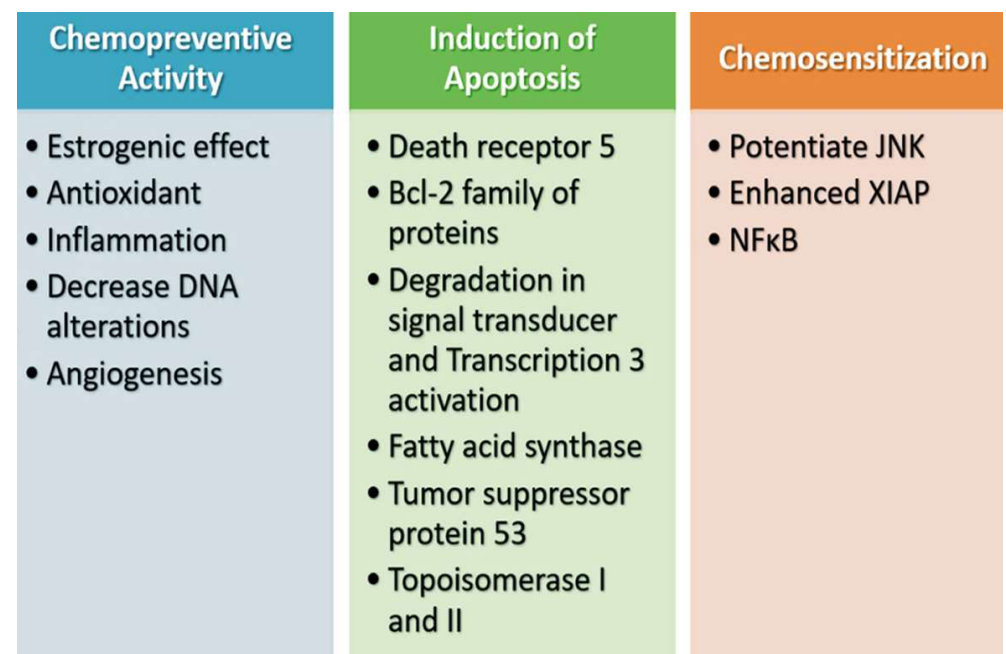

Figure 2. Luteolin's mechanism against cancer (45) 
luteolin shows a major contribution to the prevention of the rapid reproduction of cancer cells in the breast area. Luteolin also appears to have an inhibitory effect on the miRNA-21 that apoptosis cancer cells have in the same body area. Likewise, the luteolin effect on miRNA along with the way that interacts with Notch signaling were the aims of in vivo and vitro experiments conducted by Sun et al. (45).

Furthermore, luteolin has inhibitory action on rapid spread of breast cancer utilizing the Akt/FOXO3a signalling pathway. This action provides some significant outcomes; namely, the containment of breaching of breast cancer spheroids via the lymph endothelial barrier, the sensitization of breast cancer cells that considered drug-resistant, particularly to tamoxifen, by inhibiting the cyclin E2 expression and, finally, the effect that hason triple-negative breast cancer cells along with the inhibition of metastasis, cell migration, and viability of those cells (8).

Moreover, luteolin contributes to the restoration of OPCML activity that occurs in cancer cells in the breast area. The Protein Coding gene OPCML (Opioid Binding Protein/Cell Adhesion Molecule Like) is located in cells of the nervous system and has a significant engagement in two processes: the regulation of opioid receptors and signal transduction and, also, the propulsion of cell differentiation and membrane properties change (46). The action of luteolin results in the upregulation of OPCML expression in cells of breast cancer.OPCML activation along with Sp1 and NF-kB activities decrease lead to a downregulation of the levels of intracellular methylation levels. In addition, decreasing Sp1 activities affects both DNMT1 and OPCML expression (47). Furthermore, luteolin contributes to the forced prevention of TPA-induced MMP-9 expression and the inhibition of migration and invasion by provoking the formation of apoptotic bodies in MDA-MB-231 breast cancer cells that results in their death; The process of apoptosis includes cell shrinkage, DNA fragmentation, chromatin condensation, and concludes with the formation of apoptotic bodies phagocytosis by macrophages (48). Another way that luteolin provokes apoptosis in MDA-MB-231 breast cancer cells is by the inactivation of the caspase cascade and PARP. Eventually, regarding MDA-MB-231 breast cancer cells both extrinsic and intrinsic apoptotic pathways are promoted (49).

Luteolin exhibits effectiveness, which is depending on dosage and time, in blocking the IGF-1-stimulated luminal A subtype ERapositive MCF-7 cell rapid reproduction, and, also, results in diminution of the lifespan of MCF7/6 breast cancer cells. Luteolin is directly involved in various inhibitions in breast cancer cells, such as in kinases; namely protein kinase C (PKC), VRK1 and TLP2, and fatty acid synthase, as Fig. 3 illustrates. It, also, has an enhancing effect on drugs for breast cancer treatment because it functions as a chemosensitizer in regard to anticancer agents $(47,50-55)$.

Some other actions of luteolin include progress hidrance and resonance of regulatory protein expression regarding the cell cycle of breast cancer cells along with the suppression of hTERT miRNA and c Myc expression in these cells and a decrease in their telomerase activity, depending on dosage for a time period of $48 \mathrm{~h}$ and $72 \mathrm{~h}$ (11).

Moreover, luteolin shows effects on colon cancer, as well. It, particularly, restrains the development of cancer cells and has effect on antioxidant enzymes in HT-29 cells by accreting SOD and CAT activity, depending on time (up to $24 \mathrm{~h}$ ). The process of apoptosis that luteolin provokes uses the mitochondrial pathway. Western blot analysis of both the antiapoptotic and proapoptotic proteins (Bcl-2 and Bax) stipulated the luteolin effect on protein expression during apoptosis. Furthermore, there is the activation of the MAPK signalling pathway as a reaction to certain stress conditions in cells, which is involved in either death or signs of survival of these cells $(11,54-57)$.

Figure 3 presents Luteolin's signaling pathways. 


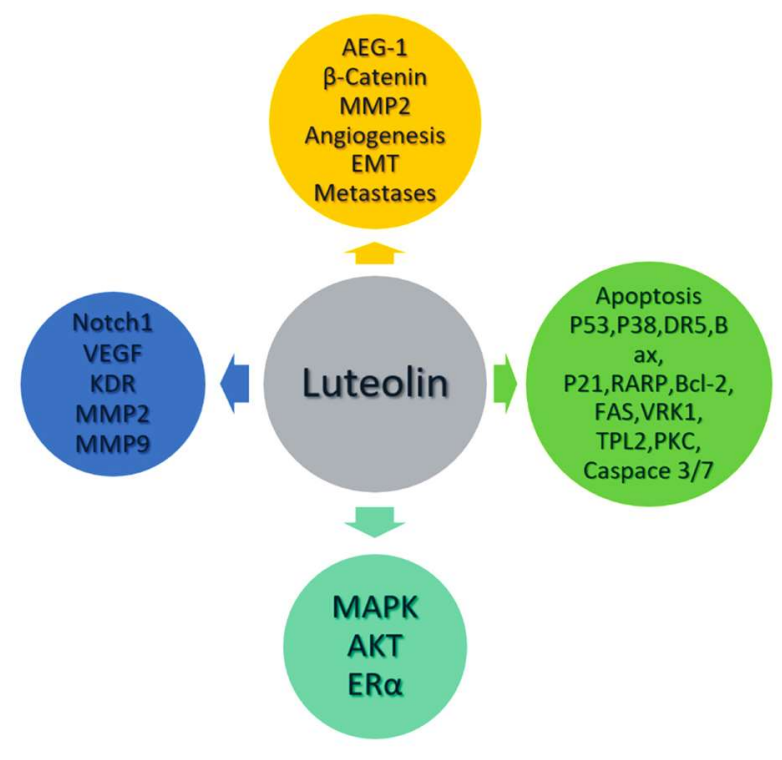

Figure 3. Luteolin signalling pathways (57)

\section{Conclusion}

Phytochemicals as bio-active compounds, have been found to play a key role in prevention of many human diseases including cancer. Plants are the source of phytochemicals thus making them widely available, safer and relatively low-cost compared with synthetic anti-cancer drugs.

Luteolin is a flavonoid, which is considered an anticancer agent, by promoting the inhibition of angiogenesis and metastasis, while preventing breast cancer formation and inducing apoptosis. Luteolin seems to be a reliable agent both for treatment and prevention of breast cancer. Although all these properties are well documented in literature, there is still lot's of ground for further research in order to define whether it may be administered solely or as an adjuvant pharmacological agent in the battle against breast cancer, as well as to determine the appropriate dosage.

\section{Conflicts of Interest and Source of Funding}

The authors declare no potential conflict of interest. There was no funding support for this study.

\section{Authors Contribution Statement}

Zacharias Fasoulakis: study conception, drafting of manuscript and analysis and interpretation of data; Antonios Koutras: drafting of manuscript and analysis and interpretation of data; Athanasios Syllaios: drafting of manuscript and analysis and interpretation of data; Dimitrios Schizas: drafting of manuscript and analysis and interpretation of data; Nikolaos Garmpis: analysis and interpretation of data, drafting of manuscript; Michail Diakosavvas: analysis and interpretation of data, drafting of manuscript; Kyveli Angelou: analysis and interpretation of data, drafting of manuscript; Georgios Tsatsaris: analysis and interpretation of data, drafting of manuscript; Athanasios Pagkalos: analysis and interpretation of data, drafting of manuscript; Emmanuel N Kontomanolis: study conception and design, acquisition of data and critical revision of manuscript.

\section{References}

1. Khattak S, Khan H. Anti-cancer Potential of Phyto-alkaloids: A Prospective Review. Curr Cancer Ther Rev. 2016;12(999):1-1

2. Park M, Kim H. Anti-cancer Mechanism of Docosahexaenoic Acid in Pancreatic Carcinogenesis: A Mini-review. J Cancer Prev. 2017; 22(1):1-5.

3. Rauf A, Uddin G, Khan H, Raza M, Zafar M, Tokuda H. Anti-tumourpromoting and thermal-induced protein denaturation inhibitory activities of $\beta$-sitosterol and lupeol isolated from Diospyros lotus L. Nat Prod Res. 2016;30(10):1205-7. Epub 2015 Jul 2

4. Cao Z, Zhang H, Cai X, Fang W, Chai D, Wen Y, et al. Luteolin Promotes Cell Apoptosis by Inducing Autophagy in Hepatocellular Carcinoma. Cell Physiol Biochem. 2017:43(5):1803-1812.

5. Boeing T, da Silva LM, Mariott M, Andrade SF de, de Souza P. Diuretic and natriuretic effect of luteolin in normotensive and hypertensive rats: Role of muscarinic acetylcholine receptors. Pharmacol Rep. 2017;69(6):1121-1124.

6. Miean KH, Mohamed S. Flavonoid (myricetin, quercetin, kaempferol, luteolin, and apigenin) content of edible tropical plants. J Agric Food Chem. 2001;49(6):3106-12.

7. Rungsung S, Singh TU, Rabha DJ, Kumar T, Cholenahalli Lingaraju M, Parida $\mathrm{S}$, et al. Luteolin attenuates acute lung injury in experimental mouse model of sepsis. Cytokine. 2018;110:333-343.

8. Ahmed S, Khan H, Fratantonio D, Hasan MM, Sharifi S, Fathi N, et al. Apoptosis induced by luteolin in breast cancer: Mechanistic and therapeutic perspectives. Phytomedicine. 2019;59:152883.

9. Stahl W, Sies H. Antioxidant activity of carotenoids. Mol Aspects Med. 2003;24(6):345-51.

10. Serpeloni JM, Barcelos GRM, Friedmann Angeli JP, Mercadante AZ, Lourdes Pires Bianchi M, Greggi Antunes LM. Dietary carotenoid lutein protects against DNA damage and alterations of the redox status induced by cisplatin in human derived HepG2 cells. Toxicol In Vitro. 2012;26(2):288-94.

11. Huang L, Jin K, Lan $H$. Luteolin inhibits cell cycle progression and induces apoptosis of breast cancer cells through downregulation of human telomerase 
reverse transcriptase. Oncol Lett. 2019;17(4): 3842-3850.

12. Elmore S. Apoptosis: a review of programmed cell death. Toxicol Pathol. 2007:35(4):495-516

13. Ernest SKM. Homeostasis. Encycl. Ecol. Five-Volume Set, 2008

14. Gerl R, Vaux DL. Apoptosis in the development and treatment of cancer. Carcinogenesis. 2005;26(2):263-70. Epub 2004 Sep 16.

15. Fink SL, Cookson BT. Apoptosis, pyroptosis, and necrosis: mechanistic description of dead and dying eukaryotic cells. Infect Immun. 2005;73(4): 1907-16.

16. Goldar S, Khaniani MS, Derakhshan SM, Baradaran B. Molecular mechanisms of apoptosis and roles in cancer development and treatment. Asian Pac $\mathrm{J}$ Cancer Prev. 2015;16(6):2129-44.

17. Nenclares P, Harrington KJ. The biology of cancer. Med (United Kingdom) 2020. https://doi.org/10.1016/..mpmed.2019.11.001.

18. Ouyang L, Shi Z, Zhao S, Wang F-T, Zhou T-T, Liu B, et al. Programmed cell death pathways in cancer: a review of apoptosis, autophagy and programmed necrosis. Cell Prolif. 2012:45(6):487-98.

19. Levine B, Kroemer G. Autophagy in the Pathogenesis of Disease. Cell 2008 https://doi.org/10.1016/i.cell.2007.12.018.

20. Kaczmarek A, Vandenabeele P, Krysko DV. Necroptosis: the release of damage-associated molecular patterns and its physiological relevance. Immunity. 2013;38(2):209-23.

21. Wardle EN, Wardle EN. Programmed Cell Death: Apoptosis. Guid. to Signal Pathways Immune Cells, 2009. https://doi.org/10.1007/ 978-1-60327-538-5_8

22. Cory S, Adams JM. The BCL2 family: Regulators of the cellular life-or-death switch. Nat Rev Cancer. 2002;2(9):647-56.

23. Kris-Etherton PM, Hecker KD, Bonanome A, Coval SM, Binkoski AE, Hilpert $\mathrm{KF}$, et al. Bioactive compounds in foods: their role in the prevention of cardiovascular disease and cancer. Am J Med. 2002; 113 Suppl 9B:71S-88S.

24. Martínez ME, Marshall JR, Giovannucci E. Diet and cancer prevention: the roles of observation and experimentation. Nat Rev Cancer. 2008;8(9): 694-703.

25. Patel S. Plant-derived cardiac glycosides: Role in heart ailments and cancer management. Biomed Pharmacother. 2016;84:1036-1041.

26. Samy RP, Gopalakrishnakone P, Ignacimuthu S. Anti-tumor promoting potential of luteolin against 7,12-dimethylbenz(a)-anthracene-induced mammary tumors in rats Chem Biol Interact. 2006:164(1-2):1-14.

27. Amin S, Khan $H$. Revival of Natural Products: Utilization of Modern Technologies. Curr Bioact Compd 2016. https://doi.org/ 10.2174/ 1573407212666160314195845

28. Farooq U, Khan A, Naz S, Rauf A, Khan H, Khan A, et al. Sedative and antinociceptive activities of two new sesquiterpenes isolated from Ricinus communis. Chin J Nat Med. 2018;16(3):225-230.

29. Jawad M, Khan H, Pervaiz S, Bawazeer SS, Abu-lzneid T, Saeed M, et al. Pharmacological validation of the anxiolytic, muscle relaxant and sedative like activities of capsicum annuum in animal model. Bangladesh J Pharmacol 2017. https://doi.org/10.3329/ bjp.v12i4.33182.

30. Khan H, Amin S. ACE Inhibition of Plant Alkaloids Targeted Approach for Selective Inhibition. Mini Rev Org Chem 2017. https://doi.org/10.2174/ 1570193x14666161201124705

31. Marya BSP, Khan H. Anti-inflammatory Potential of Alkaloids as a Promising Therapeutic Modality. Lett Drug Des Discov 2016. https://doi.org/10.2174/ 1570180813666160712224752

32. Liu RH. Potential synergy of phytochemicals in cancer prevention: mechanism of action. J Nutr. 2004;134(12 Suppl):3479S-3485S.

33. Ortholand JY, Ganesan A. Natural products and combinatorial chemistry: back to the future. Curr Opin Chem Biol. 2004;8(3):271-80.

34. Surh YJ. Cancer chemoprevention with dietary phytochemicals. Nat Rev Cancer. 2003:3(10):768-80.

35. Mitra S, Dash R. Natural Products for the Management and Prevention of Breast Cancer. Evidence-Based Complement Altern Med. 2018;2018: 8324696. eCollection 2018

36. Vinod BS, Maliekal TT, Anto RJ. Phytochemicals as chemosensitizers: from molecular mechanism to clinical significance. Antioxid Redox Signal. 2013;18(11):1307-48. Epub 2012 0ct 9 .
37. Dayem AA, Choi HY, Yang GM, Kim K, Saha SK, Cho SG. The anti-cancer effect of polyphenols against breast cancer and cancer stem cells: molecular mechanisms. Nutrients. 2016;8(9):581.

38. Ko E-Y, Moon A. Natural Products for Chemoprevention of Breast Cancer. J Cancer Prev. 2015;20(4):223-31.

39. Islam MS, Giampieri F, Janjusevic M, Gasparrini M, Forbes-Hernandez TY, Mazzoni L, et al. An anthocyanin rich strawberry extract induces apoptosis and ROS while decreases glycolysis and fibrosis in human uterine leiomyoma cells. Oncotarget. 2017:8(14):23575-23587.

40. Nabavi SF, Atanasov AG, Khan H, Barreca D, Trombetta D, Testai L, et al. Targeting ubiquitin-proteasome pathway by natural, in particular polyphenols, anticancer agents: Lessons learned from clinical trials. Cancer Lett. 2018; 434:101-113

41. Lu C, Wang W, Jia Y, Liu X, Tong Z, Li B. Inhibition of AMPK/autophagy potentiates parthenolide-induced apoptosis in human breast cancer cells. J Cell Biochem. 2014;115(8):1458-66

42. Tuorkey MJ. Molecular targets of luteolin in cancer. Eur J Cancer Prev. 2016; 25(1):65-76

43. Lin Y, Shi R, Wang X, Shen H-M. Luteolin, a Flavonoid with Potential for Cancer Prevention and Therapy. Curr Cancer Drug Targets. 2008;8(7):634-46.

44. Kashyap D, Sharma A, Tuli HS, Sak K, Punia S, Mukherjee TK. Kaempferol A dietary anticancer molecule with multiple mechanisms of action: Recent trends and advancements. J Funct Foods. 2017;30:203-219.

45. Sun DW, Zhang H Da, Mao L, Mao CF, Chen W, Cui M, et al. Luteolin Inhibits Breast Cancer Development and Progression in Vitro and in Vivo by Suppressing Notch Signaling and Regulating MiRNAs. Cell Physiol Biochem. 2015;37(5):1693-711

46. Sellar GC, Watt KP, Rabiasz GJ, Stronach EA, Li L, Miller EP, et al. OPCML at 11 q25 is epigenetically inactivated and has tumor - suppressor function in epithelial ovarian cancer. Nat Genet. 2003; 34(3):337-43.

47. Dong X, Zhang J, Yang F, Wu J, Cai R, Wang T, et al. Effect of luteolin on the methylation status of the OPCML gene and cell growth in breast cancer cells. Exp Ther Med. 2018;16(4):3186-3194.

48. Zhivotosky B, Orrenius S. Assessment of Apoptosis and Necrosis by DNA Fragmentation and Morphological Criteria. Curr Protoc Cell Biol. 2001; Chapter 18:18.3.1-18.3.23.

49. Lee J, Park SH, Lee J, Chun H, Choi MK, Yoon JH, et al. Differential effects of luteolin and its glycosides on invasion and apoptosis in MDA-MB-231 triplenegative breast cancer cells. EXCLI J. 2019:18:750-763. eCollection 2019.

50. Ruhul Amin ARM, Wang D, Zhang H, Peng S, Shin HJC, Brandes JC, et al. Enhanced anti-tumor activity by the combination of the natural compounds (-)-epigallocatechin-3-gallate and luteolin: Potential role of p53. J Biol Chem. 2010;285(45):34557-65

51. Du GJ, Song ZH, Lin HH, Han X feng, Zhang S, Yang Y ming. Luteolin as a glycolysis inhibitor offers superior efficacy and lesser toxicity of doxorubicin in breast cancer cells. Biochem Biophys Res Commun. 2008:372(3):497-502.

52. Jeon YW, Suh YJ. Synergistic apoptotic effect of celecoxib and luteolin on breast cancer cells. Oncol Rep. 2013:29(2):819-25. Epub 2012 Nov 29.

53. Baskar AA, Ignacimuthu S, Michael GP, Al Numair KS. Cancer chemopreventive potential of Luteolin-7-0-Glucoside isolated from ophiorrhiza mungos linn. Nutr Cancer. 2011;63(1):130-8

54. Lin YS, Tsai PH, Kandaswami CC, Cheng CH, Ke FC, Lee PP, et al. Effects of dietary flavonoids, luteolin, and quercetin on the reversal of epithelialmesenchymal transition in A431 epidermal cancer cells. Cancer Sci. 2011; 102(10):1829-39.

55. Gao G, Ge R, Li Y, Liu S. Luteolin exhibits anti-breast cancer property through up-regulating miR-203. Artif Cells Nanomed Biotechnol. 2019;47(1):32653271

56. Hsieh CJ, Kuo PL, Hsu YC, Huang YF, Tsai EM, Hsu YL. Arctigenin, a dietary phytoestrogen, induces apoptosis of estrogen receptor-negative breast cancer cells through the ROS/p38 MAPK pathway and epigenetic regulation. Free Radic Biol Med. 2014;67:159-70. Epub 2013 Oct 17.

57. Kang KA, Piao MJ, Ryu YS, Hyun YJ, Park JE, Shilnikova K, et al. Luteolin induces apoptotic cell death via antioxidant activity in human colon cancer cells. Int J Oncol. 2017;51(4):1169-1178. 